\title{
DNA profiling in India
}

The Indian parliament will soon discuss a bill regarding forensic DNA profiling, the terms of which will affect a vast population. It should not pass without substantial national debate and a provision for independent oversight.

The forensic successes of DNA profiling are undeniable. When used correctly, patterns obtained from short tandem repeats in genomic DNA can indicate, with high probability, whether it is likely that an individual (or their relative) was present at a crime scene or left traces on a victim's body. DNA profiles can also rule out that crime-related samples came from a particular individual. The technology has been used both to solve crimes and to exonerate the innocent. But there have also been reports of wrong convictions based on DNA evidence. No method is free of all error.

DNA profiling is now widely used around the globe. The Forensic Genetics Policy Initiative (FGPI), an organization that promotes debate on the human rights implications of DNA profiling, lists 60 countries that maintain national DNA databases, including the United Kingdom and the United States, and 34 countries that plan to introduce them. India is part of the latter group. The bill up for discussion will affect how the Indian database is generated, maintained, secured and used.

Perhaps the first question about such a database is who is included. Most countries collect profiles from a subset of individuals arrested for, charged with or convicted of a crime. Some countries require court orders; others do not. The Indian bill allows for the collection of DNA profiles without court order from suspects for the many offenses for which a police officer may make an arrest without a warrant, as well as from volunteers. It further rules that the profile of an acquitted or unconvicted person must be expunged, but only upon court order. The bill makes no such statement about dropped cases or about volunteers, whose profiles are typically forensically useful only for a particular investigation. Profiles of those convicted, even of more minor crimes, are permanently retained.

Apart from the profiles, the physical DNA samples themselves may be either stored or destroyed. There is no requirement in the draft bill for destruction of samples. But unlike a fingerprint, a person's DNA can be used for a lot more than identification. If individual DNA samples are stored, they could be analyzed for information about a person's genetic disease risks or ancestry, for example, which is private information.

Though the Indian bill does recognize the importance of privacy, the current draft includes language about use of the DNA database for "civil matters" and "other cases" that are ill defined. It mentions the use of profiles for research and protocol development. But should human samples col- lected to solve crimes be used for other purposes, including research, without donor consent? Especially considering that a database may extend far beyond convicted violent criminals to include those who have committed minor crimes, innocent people and volunteers? The bill makes no mention of obtaining informed consent. Any additional uses of DNA profiles must at the minimum require donor consent and be subject to ethical and possibly scientific oversight.

The laboratories conducting forensic DNA profiling and the databanks themselves should be held to high standards of technical competence and adherence to regulations, which must be continually monitored. This will be no easy task in a country of India's scale.

As for every powerful technology, there is the potential for misuse, whether through incompetence, sloppiness or intent. Mix-ups could lead to wrong convictions; retention of profiles could stigmatize innocent people; re-analysis of stored samples could publicize sensitive health-risk information. Although the current draft bill acknowledges that the technology has risks, it places far too much responsibility on the DNA Profiling Board both for implementing safeguards against misuse and for regulating and assessing them. The board will include eminent people occupying high positions in the country with expertise in a range of relevant subjects, but this does not mean there is no need for independent, empowered, regulatory oversight. Uncorrected, this lack of oversight would be a grave error.

The broader issues for DNA profiling, only a few of which are mentioned here, apply just as much to other countries as they do to India. (For instance, the FGPI reports that of the 28 states in the United States that collect DNA profiles before conviction, only 7 automatically expunge the profiles of the innocent.) But the sheer scale and variety of the Indian context will bring up further concerns. No top-down assessment will capture thesethough again not an easy task, there is a strong need for public discussion at the local and regional levels. Although the government invited public comment on the current version of the bill earlier this year, the reach of such a call is likely to have been very limited in the few weeks allowed and in the absence of a serious effort to include representatives from across the population.

For DNA profiling in India to be both effective and ethical, and for the likely societal benefits to be balanced against the protection of citizens' rights, vigorous public debate and ongoing oversight are indispensable. 